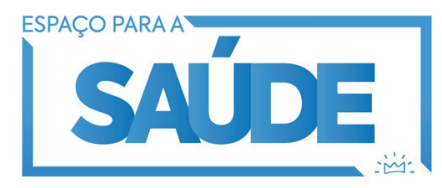

Espac. Saúde. 2021;22:e786 Doi 10.22421/1517-7130/es.2021v22.e786 (C) 2018 - ISSN 15177130

\title{
ENSAIO
}

\section{Ensino de patologia no curso de medicina}

\author{
Teaching of pathology in the course of medicine
}

Enseñanza de patología en el curso de medicina

\author{
Samya Hamad Mehanna ${ }^{1}$, Maria Cecilia Da Lozzo Garbelini ${ }^{2}$ \\ 1 Médica patologista. Mestre em Ensino de Ciências da Saúde. Docente das Faculdades Pequeno \\ Príncipe e Faculdade Evangélica Mackenzie do Paraná. Curitiba, Paraná. \\ 2 Doutora em Ciências, Professora da Graduação e do Mestrado em Ensino nas Ciências da Saúde \\ pela Faculdades Pequeno Príncipe. Curitiba, Paraná
}

\section{INTRODUÇÃo}

A Patologia, também chamada Anatomia Patológica, é uma especialidade médica responsável pelo estudo e análise de tecidos, órgãos e fluidos corporais, com propósito de realizar o diagnóstico das doenças. Em uma dimensão maior, pode-se considerar a Patologia como o ramo da Medicina que estuda as doenças e as alterações que estas provocam no organismo. Para fins educacionais a Patologia integra as ciências básicas dos cursos de graduação na área da saúde, e é responsável por elucidar informações imprescindíveis sobre alterações histológicas e fisiopatológicas das doenças, fazendo a conexão entre o ciclo básico e o ciclo clínico/internato ${ }^{1}$. Portanto, de suma importância na formação de profissionais, principalmente médicos, fornece os conhecimentos e as bases para a compreensão das doenças ${ }^{2}$.

Infelizmente e erroneamente, a Patologia e a laboração dos médicos patologistas são lembradas, muitas vezes, somente na atuação em autópsias ${ }^{3}$. A partir deste pressuposto fatual, autores defendem a necessidade de que seja dada ênfase à fisiopatologia e entendimento do mecanismo de doença, não 
se esquecendo de expor também a rotina do profissional da área. Também deve ser abordada a Patologia Cirúrgica por meio da avaliação dos diferentes métodos diagnósticos que terão serventia, para futuros médicos, no momento da investigação e manejo de seus pacientes, evitando focar em descrição histológica detalhada que não serão relevantes para a prática do médico generalista ${ }^{4}$.

\section{ENSINO DE PATOLOGIA: HISTÓRICO E METODOLOGIAS}

De uma maneira geral, o ensino-aprendizagem de Patologia deve contemplar o estudo dos processos celulares patológicos básicos e, posteriormente, o estudo das doenças dos sistemas por meio de diferentes atividades teóricas/práticas para sua consolidação. O ensino-aprendizagem da Patologia, em um primeiro contato, pode ser iniciado pela macroscopia em aulas práticas com a contemplação do acervo de peças formalizadas. Essas práticas auxiliam a aquisição de conhecimentos de anatomia e esplancnologia e o reconhecimento das lesões patológicas ${ }^{5}$.

Outra atividade que costuma ser desenvolvida é o estudo de lâminas histológicas visualizadas em aulas laboratoriais. Desta maneira, os estudantes têm contato com microscópio óptico para realizar a análise do material em colaboração com ensinamentos de Histologia Humana e alterações teciduais patológicas inflamatórias, benignas e malignas ${ }^{6}$. Com o advento de novas tecnologias, as lâminas selecionadas podem ser digitalizadas e o estudo pode ser realizado pelo computador.

A prática da medicina forense, que também cabe à especialidade, abrange as autópsias, exames minuciosos de um cadáver, realizadas por especialista qualificado para determinar o momento e a causa mortis. Uma opção de aprendizagem acontece quando os estudantes acompanham este procedimento junto aos médicos do Instituto Médico Legal ou Serviço de Verificação de Óbito. Mais adequado ainda seria realizar necrópsias acadêmicas, requisitadas pelo hospital-escola, nas quais poderiam ser correlacionados os sintomas e sinais da história clínica do paciente com os achados macroscópicos durante o procedimento e, também, com a análise histológica?

Outra opção interessante é utilizar discussões anatomoclínicas como metodologia de aprendizagem. Utilizando um caso clínico (ou também situaçãoproblema), que foi delineado para abordagem de temas específicos, os estudantes aprenderão, levantarão questionamentos e buscarão soluções baseadas em seus conhecimentos prévios. A depender do caso, o estudo da Patologia é fundamental para elucidação do caso e, assim, os estudantes vão perceber a relevância desta aprendizagem para sua prática profissional futura ${ }^{8}$.

Historicamente a Patologia no contexto do ensino tradicional, assim como nas demais disciplinas dos cursos de graduação na área da saúde, é ensinada principalmente por meio de aulas expositivas, nas quais os estudantes prestam atenção em um docente posicionado centralmente à frente da sala de aula. No currículo tradicional, a Patologia é ministrada entre as disciplinas básicas e clínicas e tem uma ligação crucial entre a ciência médica e a prática clínica. Porém, muito se discute sobre a importância da formação holística do profissional médico e da necessidade de uma combinação de diferentes métodos de aprendizagem, com o intuito de integrar os conhecimentos 9 .

Recentemente os professores de Patologia vêm se adaptando para acompanhar esta série de mudanças, com projetos curriculares que visam a integração dos conhecimentos baseada no uso de metodologias ativas de ensino-aprendizagem. A Patologia, em seu próprio fundamento, pode ter papel decisivo nesta formação, pois possibilita abordagens alternativas de ensino associadas à prática e a utilização de 
atividades diversificadas de aprendizagem como mencionado ${ }^{7}$. No Brasil, porém, são escassos os estudos e relatos de como as mudanças curriculares atingem o ensino-aprendizagem da Patologia.

$\mathrm{Na}$ proposta de currículo integrado, com a redução da carga horária em sala e estímulo de atividades autoinstrutivas, houve uma diminuição do conteúdo geral de todas as disciplinas da graduação. É necessário levar em consideração também o crescente ganho de conhecimento nas diversas áreas da medicina. Como resultado, há redução do espaço e tempo nos projetos curriculares para abordar integralmente os assuntos, visto que o curso continua com a mesma duração de seis anos.

A discussão sobre qual seria posição da Patologia num modelo de aprendizado baseado em problemas é polêmica principalmente por, muitas vezes, dispensar a atuação do patologista como docente ${ }^{10}$, sendo que este profissional poderia figurar como importante eixo interdisciplinar com o morfofuncional - fisiologia, histologia, bioquímica e radiologia, além da integração com clínica. Neste contexto, "o professor com formação em Patologia tornou-se aparentemente dispensável na formação do novo médico. Para estes professores é difícil compreender como um curso médico pode prescindir de profissionais com esta formação ou mesmo como os facilitadores poderão lidar com temas como Fisiopatologia e Anatomia Patológica, e como interpretar exames patológicos sem que seja necessária nem a graduação em Medicina. (2009, p. $51)^{» 10}$

Ademais, o problema aparentemente não está na integração da Patologia com disciplinas clínicas, mas sim no fato da Patologia ser ensinada por profissionais sem residência médica na área, na ausência do estudo morfológico (aulas de microscopia e/ou sessões de necrópsias) e sem o contato com a especialidade ${ }^{4}$. A inclusão de novas mídias tecnológicas deve ser obviamente incentivada, mas sem a substituição do especialista como facilitador do conhecimento, como observado mundialmente. Há décadas autores revelam uma queda na participação do patologista como docente e este fato instaura uma crise do ensino da Patologia ${ }^{10,11,12}$.

Outra questão importante, já apontada pela literatura, é se os estudantes de Medicina devem aprender a fazer o diagnóstico histopatológico. A resposta encontrada por pesquisas é positiva ${ }^{6}$, pois há necessidade de desenvolvimento de habilidades que incluam: melhor compreensão do processo de doença pelos estudantes; observação dos princípios gerais que estão na base de todos os processos patológicos; compreensão das dificuldades de interpretação em um exame anatomopatológico, reconhecendo limitações, o que pode ser discutido com o patologista; e a importância da correlação clínica em diversas situações ${ }^{10}$.

Ainda, também compete aos professores de Patologia estimular o interesse da temática como carreira, assim como a necessidade do envolvimento dos patologistas no planejamento e desenvolvimento curricular ${ }^{12}$. No Brasil, essas transformações certamente acontecem, e os patologistas brasileiros também concordam que há uma crise tanto no ensino da Patologia como na escolha desta como especialidade. Este tema foi amplamente discutido no encontro anual realizado pela Sociedade Brasileira de Patologia (SBP), ocorrido no ano de 2014 durante o Fórum de Ensino de Patologia ${ }^{13}$. Entre as discussões, preocupações e propostas estabelecidas pelo fórum, destacam-se:

1. Número reduzido de médicos patologistas atuando como docentes nas universidades;

2. Estímulo à escolha da Patologia como especialidade;

3. Necessidade de adaptação da metodologia de ensino para acompanhar as mudanças curriculares e o advento de novas tecnologias, com a formação e capacitação de professores com habilidades de aprendizagem ativa focadas em Patologia, objetivando correlacionar dados 
morfológicos com a prática clínica;

4. Recomendações curriculares mínimas para o ensino-aprendizagem de Patologia na graduação em medicina;

5. Montagem de um curso de capacitação docente virtual e criação de grupos de estudo para publicações relacionadas ao ensino ${ }^{13}$.

Dada a problemática descrita sobre as metodologias de ensino-aprendizagem e necessidades curriculares, dentre as diversas possibilidades de modelo de gestão pedagógica para o ensino de Patologia, em consonância com o que diz as Diretrizes Curriculares Nacionais para o curso de Medicina ${ }^{14}$, pode sobrelevar o desenvolvimento de novas competências, como defende o consagrado sociólogo Perrenoud ${ }^{15}$. O autor reconhece que competências em educação são as faculdades de mobilizar um conjunto de recursos cognitivos - como saberes, habilidades e informações - para solucionar com pertinência e eficácia uma série de situações, buscando conectar os assuntos trabalhados em sala de aula com a realidade encontrada no ambiente social dos estudantes ${ }^{15}$.

A educação médica baseada em competência é projetada para ensinar raciocínio diagnóstico e terapêutico crítico, ao invés da simples memorização das informações. Uma vantagem de aplicar o pensamento crítico ao aprendizado é que os estudantes têm uma compreensão mais aprofundada do assunto e são mais capazes de ver as conexões entre diferentes tópicos - o que, no caso do ensino de patologia, significaria conexões entre os processos patológicos/medicina diagnóstica com a prática médica clínica. Isto, claro, associado à incorporação de avaliações formativas e somativas dos estudantes que sejam voltadas para a análise do pensar e que se concentre diretamente nas competências ${ }^{16}$.

O ensino-aprendizagem por competências consiste em princípios complexos que devem ser afeiçoados às necessidades de determinada área do conhecimento. Para a Patologia, o ensino por competências deve auxiliar o aprendizado dos processos patológicos de forma adequada, estabelecendo as posições ocupadas pelos docentes e estudantes no processo. Neste contexto, os estudantes têm autonomia para expressar o que esperam obter com o estudo e os professores estabelecem os fundamentos a serem trabalhados. Cabe então, de uma maneira geral, aos professores gerenciar a classe como uma comunidade educativa, utilizar recursos pedagógicos motivadores, criar e orientar situações-problema, observá-los durante as atividades e avaliar as competências em construção ${ }^{17}$. Compete aos estudantes desenvolver as competências de dominar a leitura e a escrita de termos específicos da área de conhecimento, resolver situaçõesproblema, compreender e atuar na realidade social, saber utilizar as informações aprendidas e trabalhar em equipe. Criar uma situação que gere conflitos e estimule os estudantes a resolvê-la fará com que a teoria ganhe visivelmente uma aplicabilidade, o que consolida e integram as conexões teórico práticas ${ }^{18}$.

Alguns educadores podem tecer críticas às abordagens baseadas em competências, no sentido de serem limitadas aos comportamentos, e que este tipo de ensino-aprendizagem ignoraria a importância do conhecimento que sustenta esses desempenhos. Sabe-se que um graduado em medicina não deve apenas realizar um diagnóstico diferencial baseado em achados laboratoriais (comportamento), mas também deve entender como e por que determinada doença está ocorrendo (conhecimento). Uma resposta adequada a essa crítica é que o treinamento baseado em competências não ignora o conhecimento, como ensina a psicopedagogia: requer-se conhecimento para a manifestação de um comportamento ${ }^{19}$.

Porém, há conhecimentos de Patologia que não podem ser observados como um comportamento, e não parecem ser necessariamente relevantes para a gestão imediata de um paciente. O que fazer então? A reflexão do docente da área deve ser em perguntar o que é de fato importante para o estudante aprender com relação à determinada ciência. Ao enquadrar o ensino-aprendizagem em uma abordagem por 
competências, evita-se enfatizar os detalhes que podem ser importantes para os especialistas, mas não são para o médico generalista. É verdade que um graduado em medicina não precisa reconhecer diferentes tipos morfológicos ou listar vários critérios patológicos diagnósticos, porém todo médico precisa saber solicitar exames complementares incluindo os de anatomia patológica; explicar sobre a doença ao paciente e conseguir correlacionar o laudo recebido com os sinais e sintomas clínicos ${ }^{20}$.

\section{CONCLUSÕES}

A Patologia está presente no exercício profissional de todos os médicos, principalmente na competência dos cirurgiões e oncologistas que cuidam de seus pacientes com a ajuda dos conhecimentos advindos dos patologistas propriamente. A maioria dos estudantes de medicina não dispensa o tempo acadêmico necessário com atividades nesta área, somado a ausência de estágios observacionais, mas todos eles dependerão da Patologia para atender seus pacientes futuramente. Uma abordagem baseada em competências, conjunto de conhecimentos, habilidades e atitudes, requer que os estudantes aprendam como usar os conhecimentos de fisiopatologia na sua prática clínica. Se, como mencionado, muitos educadores da área acreditam que os estudantes não são expostos ao ensino de Patologia de forma suficiente, então a implementação da abordagem por competências seria uma alternativa de tentar resolver esta carência, incorporando firmemente a Patologia no currículo integrado como proposto pelas Diretrizes Curriculares Nacionais.

Por fim, a exposição contínua do estudante a este conteúdo, como um tema longitudinal durante o curso de graduação em medicina, fomentará o raciocínio interdisciplinar e a compreensão do que é essencial nos cuidados em saúde.

\section{REFERÊNCIAS}

1. Du Boulay C. Learning pathology: why? how? when? J Clin Pathol [Internet]. 1997, Aug [Acesso em 15 mar 2019];50(8):623-4. Disponível em: https://pubmed.ncbi.nlm. nih.gov/9301543

2. Herrmann EM, Lenski M, Steffen J, Magdalena K, Nikolaus M, Koteeswaran R, et al. A survey study on student preferences regarding pathology teaching in Germany: A call for curricular modernization Curriculum development. BMC Med Educ [Internet]. 2015, Jun [Acesso em 18 mar 2019];15(1):1-7. Disponível em: http://dx.doi.org/10.1186/ s12909-015-0381-7

3. Fenderson BA. Strategies for teaching pathology to graduate students and allied health professionals. Hum Pathol [Internet]. 2005, Feb [Acesso em 18 mar 2019];36(2):146-53. Disponível em: https://pubmed.ncbi. nlm.nih.gov/15754291

4. Pereira PF.; Souza CT, Hora DL, Possas CA, Menezes RC. O Ensino da Patologia e sua Influência na atuação de Patologistas e Infectologistas no Rio de Janeiro. Rev Bras Educ Med [Internet]. 2018, Jan-Mar [Acesso em 03 abr 2019], 42(1):216-25. Disponível em: https://www.scielo.br/j/rbem/a/ jDZqBBhtrDN4hZzWmQh8YTg/?format=pdf\&lang=pt

5. Taylor CR, Deyoung BR, Cohen MB. Pathology education: quo vadis? Hum Pathol [Internet]. 2008, Nov [Acesso em 07 abr 2019];39(11):1555-61. Disponível em: https://pubmed. ncbi.nlm.nih.gov/18789479

6. Kondratowicz GM, Smallman LA, Jones EL. How do we teach pathology? J Pathol [Internet]. 1989, Jan [Acesso em 10 abr 2019], 157(1):85-7. Disponível em: https://pubmed. ncbi.nlm.nih.gov/2921670

7. Silva AF, Ishigai M, Mauad T. Autópsias acadêmicas no Brasil - um inquérito nacional. Rev Assoc Bras [Internet]. 2014, Jan [Acesso em 15 mar 2019];60(2):145-50. Disponível em: $\quad$ https://www.scielo.br/scielo.php?script=sci arttext\&pid=S0104-42302014000200145

8. Levison DA, Fawkes RS, Macgillivray JB, Beck JS. Problem solving cases in teaching of applied pathology. Med Educ [Internet]. 1977, Jan [Acesso em 22 mar 2019];11(1):21-4. Disponível em: https://onlinelibrary.wiley. com/doi/abs/10.1111/j.1365-2923.1977.tb00555.x 
9. Campani A, Silva RG, Parente PM. Inovação pedagógica na universidade. Rev Educ \& Front. On-Line [Internet]. 2018, Jan/Abr [Acesso em 27 mar 2019];8(22):18-34. Disponível em: https://ojs.ufgd.edu.br/index.php/educacao/ article/view/9041

10. Athanazio DA, Neves FB, Boaventura CS, Athanazio PR. O ensino de Patologia nas escolas médicas está em crise? Uma revisão sobre a experiência internacional. Rev. Bras. Educ. Méd. [Internet]. 2009, Mar [Acesso em 08 mar 2019];33(1):49-54. Disponível em: https://www.scielo.br/ scielo.php?pid=S0100 $-55022009000100007 \&$ script $=$ sci abstract\&tlng=pt

11. Mattick K, Marshall R, Bligh J. Tissue pathology in undergraduate medical education: Atrophy or evolution? J Pathol [Internet]. 2004, Aug [Acesso em 29 mar 2019];203(4): 871-76. Disponível em: https://pubmed.ncbi.nlm.nih. gov/15258988

12. Domizio P. $12^{\circ}$ The Changing Role of Pathology in the Undergraduate Curriculum. In: Hall PA, Wright NA, editors. Understanding Disease: A centenary celebration of the Pathological Society. 2006, Aug:137-52.

13. Sociedade Brasileira de Patologia (Brasil). Ensino em Patologia. O Patologista [Internet]. 2014, Out/Nov/Dez [Acesso em 07 abr 2019], 118:6-9. Disponível em: http:// www.sbp.org.br/wb/wp-content/uploads/2016/07/Jornal118. pdf $>$.

14. Brasil. Ministério da Educação. Conselho Nacional de Educação. Diretrizes Curriculares Nacionais do Curso de Graduação em Medicina. Parecer CNE/CES/116/2014, de 3 de junho de 2014 [parecer na Internet]. Diário Oficial da União 6 jun 2014 [Acesso em 18 mar 2019]; Seção1,(17). Disponível em: http://portal.mec.gov.br/index. php?option=com_docman\&view=download\&alias $=15514$ pces116-14\&category_slug=abril-2014-pdf\&Itemid=30192

15. Perrenoud P. Dez Novas Competências Para Ensinar. Porto Alegre: Artmed Editora, 2002.
16. The Foundation for Critical Thinking [homepage na internet], Critical Thinking Development: A Stage Theory [acesso em 01 abr 2019]. Disponível em: https://www. criticalthinking.org

17. Melo-Júnior MR, Araújo-Filho JS, Patu VR, Machado $\mathrm{MF}$, Pontes-Filho NT. Integrando o ensino da patologia às novas competências educacionais. Ciências \& Cognição [Internet]. 2007, Dez [Acesso em 05 abr 2019];12(12):110-14. Disponível em: http://www.cienciasecognicao.org/pdf/v12/ m347177.pdf

18. Feurwerker, LC. Mudanças na educação médica: os casos de Londrina e Marília. Interface - Comunic, Saúde, Educ [Internet]. 2002, Ago [Acesso em 20 mar 2019];6(11):13942. Disponível em: https://www.scielo.br/j/icse/a/ GpnLNtGqVmpgZLGK6F3FsbB/?format=pdf\&lang=pt

19. Fleury MT, Fleury A. Construindo conceito competência. Rev Adm Contemp. [Internet]. 2001, Set [Acesso em 12 mar 2019];5(spe):183-196, . Disponível em: $\quad$ https://www.scielo.br/scielo.php?script=sci_ arttext\&pid=S1415-65552001000500010

20. Ford, J.; Pambrun C. Exit competencies in pathology and laboratory medicine for graduating medical students: the Canadian approach. Hum Pathol [Internet]. 2015, May [Acesso em 28 mar 2019];46(5):637-42. Disponível em: https://pubmed.ncbi.nlm.nih.gov/25776028/ 